\title{
Cortical lag screw fixation for the management of mandibular injuries
}

\author{
Shadia Abdel-Hameed Elsayed ${ }^{1,2}$ \\ ${ }^{l}$ Department of Oral and Maxillofacial Surgery, Faculty of Dental Medicine for Girls, \\ Al-Azhar University, Cairo, Egypt, ${ }^{2}$ Department of Oral and Maxillofacial Surgery, \\ Taibah University Dental College \& Hospital, Al-Madinah Al-Munawwarah, Saudi Arabia
}

\begin{abstract}
J Korean Assoc Oral Maxillofac Surg 2020;46:393-402)
Objectives: Here, we present cases of mandibular fracture that were managed with the cortical lag screw fixation technique (CLSFT) in order to critically evaluate technique indications and limitations of application at various fracture sites.

Materials and Methods: This was a retrospective cohort study. The study sample was composed of patients suffering from mandibular fractures that were treated by the CLSFT. The outcome variables were fracture type, duration of surgery, number of screws, and pattern of application. Other study categories included patient demographics and causes of injury. Chi-square tests were used to assess descriptive and inferential statistical differences, and the $P$-value was set at 0.05 .

Results: Thirty-three patients were included in the study sample, with a mean age of $30.9 \pm 11.5$ years and a male predominance of $81.8 \%$. The technique was applied more frequently in the anterior mandibular region (51.5\%) than in other sites. Double CLSFT screws were required at the symphysis and parasymphysis, while single screws were used for body and angle regions. No intraoperative and postoperative variables were significantly different except for surgical duration, which was significantly different between the sites studied $(P=0.035)$.

Conclusion: We found that CLSFT is a rapid, cost-effective technique for the fixation of mandibular fractures yielding good treatment results and very limited complications. However, this technique is sensitive and requires surgical expertise to be applied to mandibular fractures that have specialized characteristics.
\end{abstract}

Key words: Fractures, Mandibular fracture, Fixation, Fracture types

[paper submitted 2020. 5. 29 / revised 2020. 8. 11 / accepted 2020. 8. 14]

\section{Introduction}

The term "lag screw" describes both a particular form of screw design and a surgical technique. "Lagging" refers to "covering up", as the bone under the head of the screw covers or lags the underlying bone ${ }^{2}$. While the lag screw technique has only a limited role in maxillofacial osteosynthesis, it is commonly used in orthopedic surgery ${ }^{3,4}$. It was originally introduced to oral and maxillofacial surgery by Brons and Boering $^{5}$, who concluded that the lag screw compresses frac-

\section{Shadia Abdel-Hameed Elsayed \\ Department of Oral and Maxillofacial Surgery, Faculty of Dental Medicine for Girls, Al-Azhar University, Yusuf Abbas St., Nasr City, Cairo 11727, Egypt TEL: +20-224051396 FAX: +20-223868051 \\ E-mail: shadiaelsayed@azharedu.eg \\ ORCID: https://orcid.org/0000-0002-3348-3382}

(C) This is an open-access article distributed under the terms of the Creative Commons Attribution Non-Commercial License (http://creativecommons.org/ licenses/by-nc/4.0/), which permits unrestricted non-commercial use, distribution, and reproduction in any medium, provided the original work is properly cited. Copyright (C) 2020 The Korean Association of Oral and Maxillofacial Surgeons. All rights reserved. ture segments, and hence is classified as a rigid internal type of fixation.

The original true lag screw fixation technique involved a unique fabrication design. There are no screw threads in the section of the screw shaft nearest to the head, with the shaft size in this area equal to the total screw diameter in the threaded zone ${ }^{6}$. The compressive force of the head of the screw against bone is thereby transmitted to the bone that is secured to the threaded screw portion. This technique is costly and not widely available in all countries, as many are not served by maxillofacial suppliers and manufacturing companies. Meanwhile, the modern lag screw technique uses a screw with threads along the entire length and is applied using a special technique that is different from the true lag technique and is therefore cheaper and more widely available ${ }^{7}$.

In the past, the main indication for compression using lag screws was in the management of oblique fractures, whereby one section of mandibular cortex is split longitudinally from another for some distance through the cancellous bone. In 
this context, the technique is referred to as the gliding sliding principal $^{8}$. No additional instrumentation is required for this technique except for special true lag screws, with threads that engage only the inner boneplate ${ }^{9}$.

The cortical lag screw fixation technique (CLSFT) is performed using ordinary titanium cortical screws that are threaded for the entire length, rather than true lag screws ${ }^{10}$. The procedure depends on the drilling technique itself and requires two different drill diameters ${ }^{11}$.

The true lag screw technique has been used and studied for the treatment of anterior mandibular fractures and other locations of mandibular fractures, such as those at the mandibular angle ${ }^{12}$ and body ${ }^{13}$, and has also been used to reduce condylar fracture, as first described by Petzel and Bülles ${ }^{14}$ and utilized by others ${ }^{4,14-17}$. It is used in various surgeries such as genioplasties, sagittal split ramus osteotomies, bone graft fixation, and alveolar ridge augmentation ${ }^{18}$. Despite the many applications of the true lag technique, the CLSFT using normal threaded screws has not been thoroughly investigated as an alternative.

The goal of this study was to present cases of mandibular fracture treated with CLSFT in our institute in order to critically evaluate its indications, contraindications, techniques, limitations, and potential complications at different mandibular fracture sites.

\section{Materials and Methods}

\section{Study design and setting}

This study included 33 patients treated at Al-Azhar University Hospital, Faculty of Dental Medicine for Girls, Cairo, Egypt from October 2007 to October 2017. They suffered from mandibular fractures at different sites that were treated with CLSFT through open reduction and internal fixation. The present study was reviewed and ethically approved by the Al-Azhar University Ethical Committee Board (No. PD-
P-020-004) and conducted in compliance with the human research ethics principles in the Declaration of Helsinki (2008). All patients provided written informed consent prior to surgery.

\section{Selection criteria}

The present study included all mandibular fracture cases fixated by double or single CLSFT during the study period. Selected patients were free from any systemic diseases that could interfere with surgery or bone healing. Any cases that were fixated by the true lag screw technique or any other means of fixation were excluded.

\section{Study variables}

The sites of the fractures were treated as predictors. The outcome variables were fracture characteristics (type, side, cause, and degree of displacement). Other categories of analysis included number of CLSFT screws, pattern of application, and duration of application.

\section{Data collection}

1) Preoperative evaluation

A complete history was acquired and registered for each patient according to a standard protocol. Systematically, the clinical review was conducted in two phases, extraoral and intraoral. Examinations were performed to detect potential lacerations, swelling, ecchymosis, facial asymmetry or malocclusion, deformity of the mandibular bony contour, and any restrictions of mandibular movement (opening, lateral movements, protrusive movements, and maximum interincisal openings).(Fig. 1. A)

General facial palpation was conducted with particular attention provided to the area around the mandible that was palpated bimanually, beginning with the condylar region
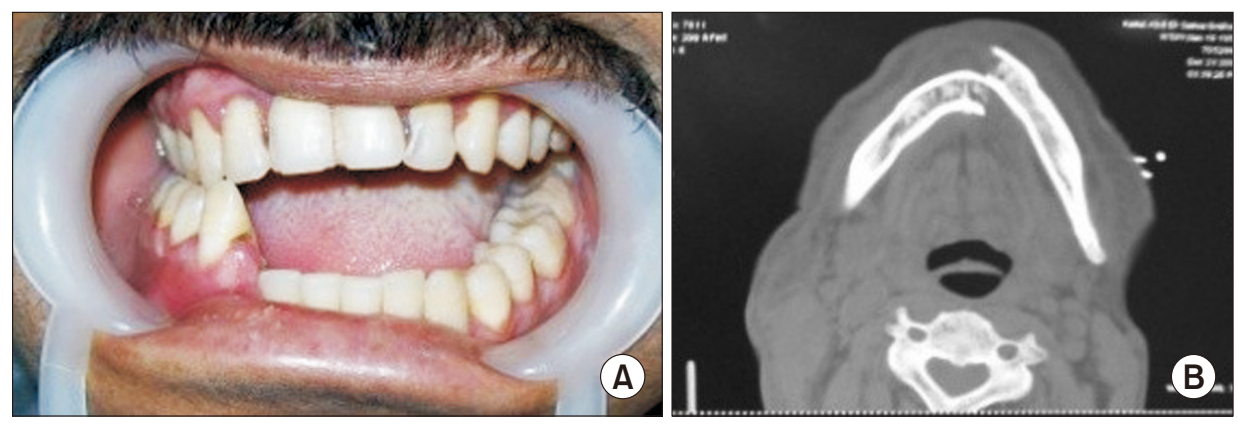

Fig. 1. A. Preoperative photograph showing displacement of right parasymphyseal fracture, malocclusion, and step deformity. B. Preoperative computed tomography (axial view) showing displaced parasymphyseal mandibular fracture.

Shadia Abdel-Hameed Elsayed: Cortical lag screw fixation for the management of mandibular injuries. $J$ Korean Assoc Oral Maxillofac Surg 2020 
and progressing over the mandible to identify any areas of tenderness, phase deformities, or bony crepitus. The lower lip and chin area were examined to detect any signs of nerve dysfunction, paresthesia, or anesthesia. The teeth were also palpated for tenderness or mobility on both sides of fracture lines.

\section{2) Radiographic examination}

Preoperative digital orthopantomogram was the standard radiography for initial assessment of the type of fracture line. Other views were requested as necessary, such as posteroanterior or computed tomography.(Fig. 1. B) These views were used to determine fracture direction and number of fracture lines. Diagnosis was based upon patient history and clinical and radiographic examinations, and the treatment plan was selected accordingly.

\section{3) Preoperative preparations}

At initial presentation, special preparations were taken before proceeding with the surgical phase of the treatment, including care of any soft tissue lacerations and wound debridement, and support and reduction of the fractured bony segments using both maxillary and segmented mandibular arch-bars at the fracture line or Ivy loops. If the fractures were severely displaced, gradual reduction was performed using elastics 24 hours before maxillofacial mandibular fixation (MMF).

Patients fasted for eight hours before surgery. All patients received $1.5 \mathrm{~g}$ of sulbactam/ampicillin (Unasyn $1.5 \mathrm{~g}$ vial; Pfizer, Cairo, Egypt). We administered 1,500 IM units of tetanus antitoxin (tetanus antitoxin; Pasteur Merieus, Lyon, France) in cases of soft tissue injuries contaminated by dirt. The patients were anesthetized using a cuffed tube and a mixture of fluthane/oxygen gas. The intraoral and extraoral regions were scrubbed using betadine (povidone-iodine; The
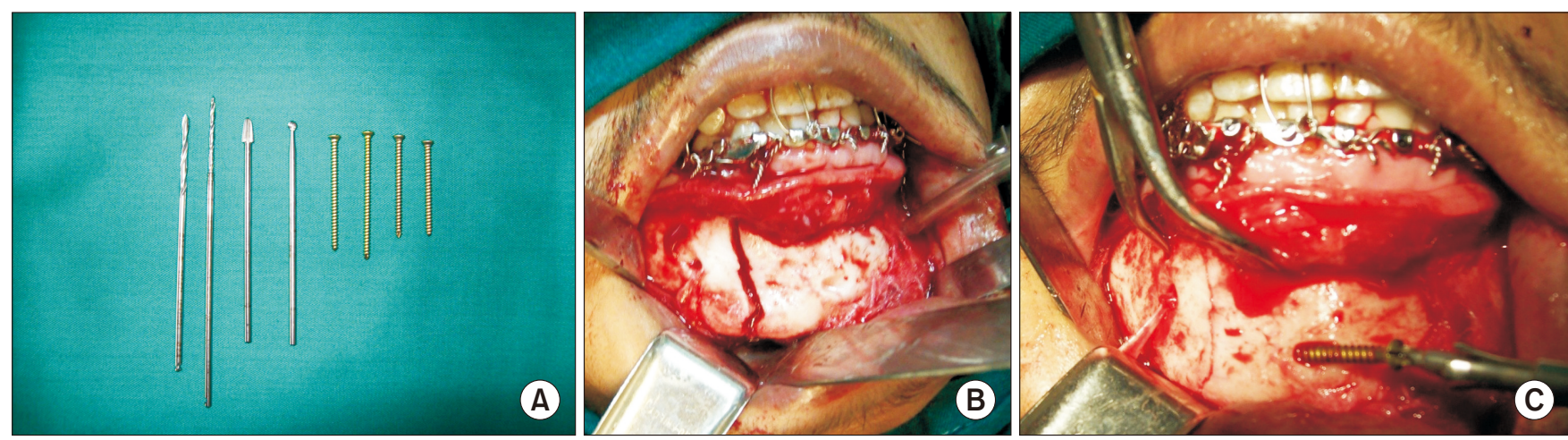

Fig. 2. A. Photograph showing drills and screws used in cortical lag screw fixation technique $(2.4 \mathrm{~mm}$ and $1.8 \mathrm{~mm}$ drill bits, pear and round shaped burs for countersinking and $2.4 \mathrm{~mm}$ screws of different lengths). B. Intraoperative exposure of a linear parasymphyseal fracture. C. Fracture reduction and pre-compression using bone clamp forceps and screwing of the first screw.

Shadia Abdel-Hameed Elsayed: Cortical lag screw fixation for the management of mandibular injuries. J Korean Assoc Oral Maxillofac Surg 2020
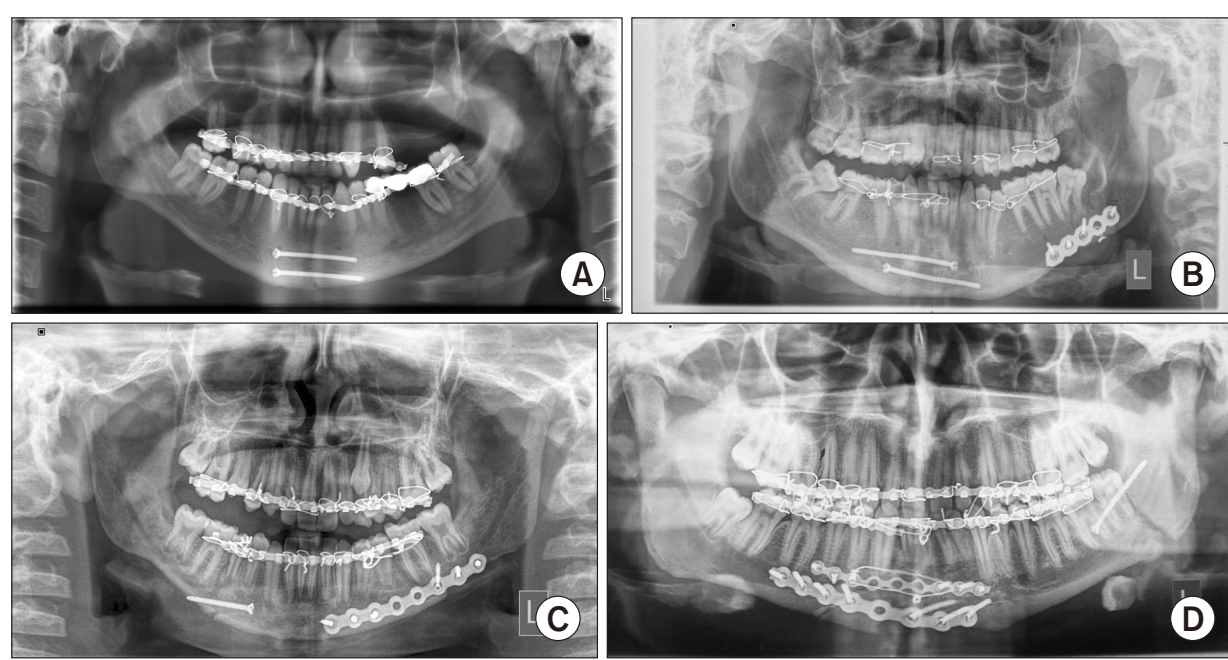

Fig. 3. A. Postoperative digital orthopantomogram radiograph showing perfect reduction and fixation of the symphyseal fracture using double lag screws in the same direction. B. Reduction and fixation of parasymphyseal fracture using double lag screws in the opposite direction. C. Perfect reduction and fixation of body fracture using a single lag screw. D. Reduction and fixation of angle fracture using a single lag screw.

Shadia Abdel-Hameed Elsayed: Cortical lag screw fixation for the management of mandibular injuries. $J$ Korean Assoc Oral Maxillofac Surg 2020 
Nile Company, Mundipharma, Switzerland).

\section{Surgical technique of CLSFT}

CLSFT was performed using ordinary titanium cortical screws threaded to the whole length. The procedure used depended on the drilling technique. We used two different drill diameters: a smaller drill diameter in the distal fragment hole, or the traction hole $^{10}$, and a larger drill equal to the diameter of the outer screw threads in the outer fractured segment so that when the screw was tightened the threads would not engage the outer cortex. We also took care to maintain sufficient distance between the countersink and the fracture site to allow for satisfactory compression ${ }^{11}$.(Fig. 2. A)

In the region of the symphysis and parasymphysis, two cortical titanium (2.4 mm diameter and $28-40 \mathrm{~mm}$ length; Synthes Maxillofacial, Oberdorf, Switzerland) were used. In our technique, the traction hole was first drilled using a smaller drill bit $(1.8 \mathrm{~mm})$ that crossed the fracture line from the outer buccal cortex to reach the opposite cortex, and then the gliding hole in the near cortex was drilled using a larger drill bit $(2.4 \mathrm{~mm})$. Preload was applied with bone clamps.(Fig. 2. B, 2. C)

Visualizing the exit site of the drill bit on the buccal side of the far segment is important to maintain an appropriate distance from the fracture line. The screw length was measured by means of a depth gauge. A second lag screw was similarly placed from the same side or in the opposite direction to the first screw. Screws were tightened by hand using a crosshead screwdriver until complete reduction and compression of the fracture was obtained. To avoid palpability the head of the screw was counter-sunk.(Fig. 3. A, 3. B) Just one CLSFT screw could be applied at the body area. The fracture line was maintained strictly as a broad oblique surface fracture line and drilling was performed for the parasymphysis area.(Fig. 3 . C)

At the angle region, a single lag screw was placed via intraoral posterior vestibular incision. The screw was tightened until adequate compression was achieved. The technique used for fixation of CLSFT in the angle region was previously described in detail by Elsayed et al. ${ }^{12}$ and applied in the present study in the same manner.(Fig. 3. D)

Deep resorbable sutures ( 2 horizontal mattress sutures) were inserted in the mentalis muscle to prevent lip and chin ptosis, then the mucosa was continuously repaired with resorbable sutures, and a pressure dressing was applied to the area to prevent the development of hematoma and maintain the mentalis muscle position. The MMF was removed at the end of the operation, and occlusion was rechecked.

\section{Treatment of concomitant mandibular fractures}

Concomitant mandibular fractures were found in 15 cases (45.5\%). One patient suffered from an associated clavicle fracture. Two patients suffered from an associated left humerus fracture and one patient suffered from rib fracture and pneumothorax preoperatively at the time of admission. The intraoral vestibular approach was used for all cases associated with concomitant mandibular fractures and fractures were fixed with double miniplates or a single heavy plate.

Unfavorable displaced subcondylar fractures were found in 2 patients in addition to anterior mandibular fractures. Subcondylar fractures were approached intraorally and fixed with double miniplates. One patient had a sagittal subcondylar fracture that was treated conservatively.

CLSFT was applied in two anterior concomitant maxillary fractures, where the fracture occurred in the area of the anterior maxillary fissure exactly in the midline, and the compression achieved successfully reduced the two maxillary bones and made the fracture line unnoticeable after reduction. The drilling technique was performed exactly as described for fractures of the anterior mandibular symphysis.

\section{Data analysis}

Descriptive characteristics for the study variables were tabulated and analyzed using chi-square tests for comparisons of fracture sites and associations with investigated categorical variables of postoperative complications and surgical duration. $P<0.05$ were considered significant. Statistical analysis was performed using SPSS (ver. 16.0; SPSS, Chicago, IL, USA).

\section{Results}

In this study, the surgical procedures included 33 internal fixations of mandibular fractures in 33 patients of both sexes (27 males and 6 females) who met our criteria for inclusion in the study and were fixated via CLSFT. The numbers of CLSFT screws used in the present investigation were two for the symphysis and parasymphysis and one for body, angle, and anterior maxillary regions.

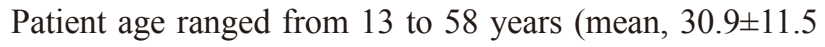
years). The fracture etiologies were road traffic accidents in 
Table 1. Descriptive characteristics of the fracture site variables and demographic characteristics of the study sample

\begin{tabular}{|c|c|c|c|c|c|c|}
\hline Variable & Category & Total & Body & Parasymphyseal & Symphyseal & Angle \\
\hline Fracture type & Site & $33(100)$ & $6(18.2)$ & $9(27.3)$ & $8(24.2)$ & $10(30.3)$ \\
\hline Age (yr) & Range, $13-58$ yr & $30.97 \pm 11.58$ & $22.50 \pm 13.44$ & $23.22 \pm 8.77$ & $31.10 \pm 8.70$ & $30.00 \pm 11.31$ \\
\hline \multirow[t]{2}{*}{ Sex } & Male & $27(81.8)$ & 6 & 9 & 6 & 6 \\
\hline & Female & $6(18.2)$ & 0 & 0 & 2 & 4 \\
\hline \multirow[t]{3}{*}{ Side } & Right & $14(42.4)$ & 2 & 7 & 2 & 3 \\
\hline & Left & $16(48.5)$ & 4 & 2 & 3 & 7 \\
\hline & Midline & $3(9.1)$ & 0 & 0 & 3 & 0 \\
\hline \multirow[t]{5}{*}{ Cause } & Fall & $9(27.3)$ & 0 & 5 & 4 & 0 \\
\hline & Motorcycle & $8(24.2)$ & 1 & 2 & 2 & 3 \\
\hline & Car accident & $11(33.3)$ & 3 & 2 & 2 & 4 \\
\hline & Animal kick & $2(6.1)$ & 2 & 0 & 0 & 0 \\
\hline & Interpersonal violence & $3(9.1)$ & 0 & 0 & 0 & 3 \\
\hline \multirow[t]{6}{*}{ Associated fractures } & Angle & $5(15.2)$ & 0 & 5 & 0 & 0 \\
\hline & Condylar & $2(6.1)$ & 0 & 0 & 0 & 2 \\
\hline & Subcondylar & $3(9.1)$ & 0 & 1 & 2 & 0 \\
\hline & No & $18(54.5)$ & 5 & 3 & 6 & 4 \\
\hline & Maxillary fracture & $2(6.1)$ & 1 & 0 & 0 & 1 \\
\hline & Symphyseal & $3(9.1)$ & 0 & 0 & 0 & 3 \\
\hline Fracture & Mild & $12(36.4)$ & 5 & 1 & 2 & 4 \\
\hline \multirow[t]{2}{*}{ displacement } & Moderate & $18(54.5)$ & 1 & 6 & 6 & 5 \\
\hline & Severe & $3(9.1)$ & 0 & 2 & 0 & 1 \\
\hline \multirow[t]{2}{*}{ No. of screws } & $\begin{array}{l}\text { Single lag screw } \\
\text { fixation technique }\end{array}$ & $16(48.5)$ & 6 & 0 & 0 & 10 \\
\hline & $\begin{array}{l}\text { Double lag screw } \\
\text { fixation technique }\end{array}$ & $17(51.5)$ & 0 & 9 & 8 & 0 \\
\hline
\end{tabular}

Values are presented as number $(\%)$, mean \pm standard deviation, or number only.

Shadia Abdel-Hameed Elsayed: Cortical lag screw fixation for the management of mandibular injuries. J Korean Assoc Oral Maxillofac Surg 2020

19 patients, assault in 3 patients, falls in 9 patients, and animal kicks in 2 patients. Table 1 provides all details about age, sex, etiology, fracture site, and concomitant fractures. The intraoral approach was used in all cases. The mean time from incision to fracture fixation did not exceed one hour, and operative time in the body and angle regions was shorter than in anterior sites where two screws were inserted $(P=0.03)$.

Electrocauterization was required in only one patient due to excessive bleeding in the molar region during the dissection of the vestibular incision. All patients had teeth involved in the fracture line and these were retained in all cases except in one case at the time of reduction, as the lower canine involved was grossly broken and mobile, necessitating its extraction.

Table 1 indicates that the CLSFT principal mainly applied in the areas of the symphysis and parasymphysis (51.5\%) followed by the angle and body regions $(30.3 \%$ and $18.2 \%$, respectively). The sample was $81.8 \%$ male, but the sex ratio did not differ significantly between sites $(P=0.07)$.

\section{Preoperative clinical and radiographic findings}

Fractures were treated within 1 to 10 days of injury incidence. At the time of admission all patients were conscious, alert without any systemic problems except four patients who were first admitted to the ICU (intensive care unit) in coma after trauma, and then to the neurosurgical department for monitoring and controlling neurological conditions. All patients had intraoral lacerations related to the fracture site, and 4 also had extraoral skin lacerations. Ten cases had severe swelling in the fracture area with remarkable facial asymmetry and severe clinically and radiographically obvious displacement of fracture segments, whereas moderate swelling was noticed in 9 patients and mild swelling was observed in 14 patients.

Post-traumatic malocclusion was identified preoperatively in all cases as patients suffered from varying degrees of occlusal disturbances (malocclusion and step deformity, mobility, or open bite). All of the patients had limited mandibular movement. The maximum preoperative interincisal mouth opening was 10-20 $\mathrm{mm}$. Two patients presented with lower lip numbness related to the fracture side.

\section{Postoperative clinical findings}

Minimal edema was immediately observed postoperatively in $60.6 \%$ of cases that started to resolve on the fourth day and disappeared on the seventh day. In general, all incisions healed uneventfully. Incision lines that were hidden became fainter by the end of the follow-up period. Postoperatively, 
Table 2. Correlations between lag screw osteosynthesis site and outcome variables

\begin{tabular}{|c|c|c|c|c|c|c|c|}
\hline Variable & Category & Total & Body & Parasymphyseal & Symphyseal & Angle & $P$-value \\
\hline $\begin{array}{l}\text { Mandibular } \\
\text { fracture site }\end{array}$ & Site & $33(100)$ & $6(18.2)$ & $9(27.3)$ & $8(24.2)$ & $10(30.3)$ & - \\
\hline $\begin{array}{l}\text { Surgical time } \\
(\text { min) }\end{array}$ & $\begin{array}{l}\text { Range, } 30-60 \text { min } \\
\text { Double lag screw } \\
\text { fixation technique }\end{array}$ & $\begin{array}{c}45.36 \pm 9.54 \\
17(51.5)\end{array}$ & $\begin{array}{c}32.50 \pm 9.55 \\
0\end{array}$ & $\begin{array}{c}53.67 \pm 5.11 \\
9(27.3)\end{array}$ & $\begin{array}{c}48.80 \pm 9.94 \\
8(24.2)\end{array}$ & $\begin{array}{c}40 \pm 0 \\
0\end{array}$ & $0.035 *$ \\
\hline $\begin{array}{l}\text { Postoperative } \\
\text { edema }\end{array}$ & $\begin{array}{l}\text { Mild } \\
\text { Moderate } \\
\text { Severe }\end{array}$ & $\begin{array}{c}20(60.6) \\
11(33.3) \\
2(6.1)\end{array}$ & $\begin{array}{c}3(9.1) \\
3(9.1) \\
0\end{array}$ & $\begin{array}{l}8(24.2) \\
1(3.0) \\
0\end{array}$ & $\begin{array}{c}6(18.2) \\
2(6.1) \\
0\end{array}$ & $\begin{array}{l}3(9.1) \\
5(15.2) \\
2(6.1)\end{array}$ & 0.10 \\
\hline $\begin{array}{l}\text { Wound } \\
\text { dehiscence }\end{array}$ & $\begin{array}{l}\text { Yes } \\
\text { No }\end{array}$ & $\begin{array}{c}1(3.0) \\
32(97.0)\end{array}$ & $\begin{array}{c}0 \\
6(18.2)\end{array}$ & $\begin{array}{c}0 \\
9(27.3)\end{array}$ & $\begin{array}{c}0 \\
8(24.2)\end{array}$ & $\begin{array}{l}1(3.0) \\
9(27.3)\end{array}$ & 0.49 \\
\hline $\begin{array}{l}\text { Postoperative } \\
\text { infection }\end{array}$ & $\begin{array}{l}\text { Yes } \\
\text { No }\end{array}$ & $\begin{array}{c}1(3.0) \\
32(97.0)\end{array}$ & $\begin{array}{c}0 \\
6(18.2)\end{array}$ & $\begin{array}{c}0 \\
9(27.3)\end{array}$ & $\begin{array}{c}0 \\
8(24.2)\end{array}$ & $\begin{array}{l}1(3.0) \\
9(27.3)\end{array}$ & 0.4 \\
\hline $\begin{array}{l}\text { Postoperative } \\
\text { paresthesia }\end{array}$ & $\begin{array}{l}\text { Yes } \\
\text { No }\end{array}$ & $\begin{array}{r}4(12.1) \\
29(87.9)\end{array}$ & $\begin{array}{c}0 \\
6(18.2)\end{array}$ & $\begin{array}{l}1(3.0) \\
8(24.2)\end{array}$ & $\begin{array}{l}1(3.0) \\
7(21.2)\end{array}$ & $\begin{array}{l}2(6.1) \\
8(24.2)\end{array}$ & 0.7 \\
\hline $\begin{array}{l}\text { Postoperative } \\
\text { malocclusion }\end{array}$ & & $1(3.0)$ & 0 & 0 & 0 & $1(3.0)$ & 0.49 \\
\hline
\end{tabular}

$* P<0.05$.

Values are presented as number $(\%)$ or mean \pm standard deviation.

Shadia Abdel-Hameed Elsayed: Cortical lag screw fixation for the management of mandibular injuries. J Korean Assoc Oral Maxillofac Surg 2020

proper occlusion was achieved in all patients and maintained during the follow-up period except for one patient with an angle fracture who was stabilized via single CLSFT and required MMF for 2 weeks in conjunction with lag fixation. (Table 2)

Stability of osteosynthesis devices was tested immediately intraoperatively, using bimanual mobility tests of the fractured segments. It was very difficult to place a second screw on more posterior angle fracture lines. Palpation of the inferior border revealed properly aligned segments in all patients with no step deformities except in two cases of parasymphyseal fractures, as the step was only present at the inferior border and did not affect occlusion.

Four cases (12.1\%) had lower lip numbness related to the side of the fracture but this number was not significant $(P=0.7)$. By the end of the second week, considerable improvement was reported by these patients. At end of the study, after a period of six months, all affected patients had regained normal mental nerve function without permanent effects.

Patient compliance was good and none reported any discomfort from the screws, so they were maintained in place until the end of the study period. Loose screws were not observed in any patient. Regaining of the interincisal mouth opening was rapid and the maximum mouth opening ranged from $25-28 \mathrm{~mm}$ immediately after the operation to $39-45 \mathrm{~mm}$ after one month. All concomitant fractures healed uneventfully without complications.

\section{Postoperative radiographic findings}

The immediate postoperative radiographs, taken in the first week, showed considerable narrowing of the fracture gap. One month postoperatively, the fracture lines were easily identified. At three months postoperatively, the fracture lines were unidentifiable in all cases. Six month postoperative radiographs revealed satisfactory bone healing and fracture lines could not be identified in any cases. None of the patients showed nonunion or malunion.

\section{Discussion}

Here, we present our experience in managing maxillofacial fractures using the CLSFT instead of true lag or other heavy plates and screws. We present cases managed with CLSFT in order to critically evaluate technique indications and limitations of its implementation at various sites of mandibular fracture that demonstrate the best outcomes of clinical practice.

Although true lag screws are more common in orthopedic surgery $^{19}, 2.4 \mathrm{~mm}$ cortical screws threaded along the entire length were used in the current study. This diameter differed from that used for fixing parasymphyseal fractures by Kallela et al. ${ }^{20,21}$, who used $2.7 \mathrm{~mm}$ and $2.0 \mathrm{~mm}$ screws. In the lag screwing technique, the application of a single lag screw in the symphysis area may cause fracture segments to rotate and for this reason 2 lag screws were used in the symphysis region in the present study. However, due to the presence of neurovascular structures and teeth apices, only single lag 
screws were applied in the body and angle areas. The lag screws must be of sufficient length, longer than $20 \mathrm{~mm}$. In the current study, the length of the screws used ranged from $28-40 \mathrm{~mm}$.

The most commonly indicated conditions for the application of the CLSFT in the present study were symphyseal and parasymphyseal fractures $(51.5 \%)$ followed by fractures of the body and angle (48.5\%), and our findings agreed with those of Tiwana et al..$^{22}$ and Terheyden et al. ${ }^{10}$. No condylar fractures were fixed with lag screws in this study sample.

Advantages of CLSFT include that it provides very strong, rigid fixation when properly applied and guarantees perfectly stabilized fractures, achieving primary bone healing with minimal use of osteosynthesis devices and lower costs in terms of operative time and material price ${ }^{23}$. However, the CLSFT is sensitive, as it would be difficult to counter-sink screws when the outer cortex is comminuted or fragmented ${ }^{16}$ and therefore it is not suggested in every case ${ }^{15}$.

The technique used for CLSFT placement in this study was different from that described by Ellis and Ghali ${ }^{6}$, Niederdellmann et al. ${ }^{24}$ and Kallela et al. ${ }^{20}$, as we first drilled the traction hole using a smaller drill bit $(1.8 \mathrm{~mm})$ that crossed the fracture line from the outer buccal cortex to the opposite cortex, followed by drilling of the gliding hole in the near cortex using a larger drill bit $(2.4 \mathrm{~mm})$.

Using this technique, we found that the eccentricity at the traction hole was minimal, therefore reducing the occurrence of malalignment that may occur during screw tightening. This technique was previously used in another study ${ }^{25}$. However, in more commonly-used techniques, drilling of the gliding hole is performed first in the near cortex followed by drilling of the traction hole through the gliding hole, which requires mandatory use of drill guides.

Placement of the incision in the oral cavity allows for superb exposure of a large part of the facial skeleton and the advantage of a fully hidden scar, as well as a rapid and safe mandibular vestibular approach. The intraoral approach provides good surgical exposure in all directions, allowing internal fixation of all concomitant mandibular fractures such as associated subcondylar and other side fractures. This eliminates the time needed for dissection in extraoral approaches. The fracture site was visualized simultaneously with dental occlusion, reducing the risk of postoperative malocclusion. This technique follows Ellis and Graham ${ }^{26}$ and several other studies $^{27,28}$ that recommend the use of intraoral incisions. On the other hand, Forrest ${ }^{29}$ inserted lag screws via small incisions transmucosally or percutaneously after fracture reduction. Meanwhile, it has been reported that the intraoral approach to angle fractures is the most difficult, requiring more time for the use of transbuccal trocar or right-angled screwdrivers for screw fixation, but the intraoral approach used with the lag screw technique does not result in difficulty in fixation of the lag screw except for cases requiring the insertion of a second screw, as the mandibular canal was approximate and the space available was very limited ${ }^{12}$.

In the current study, we noted that the more recent the fracture, the easier the reduction and the faster the fixation because granulation tissue was easily removed and the fracture was easily mobilized and reduced. All patients were treated within 1-10 days of the date of injury. This finding is in agreement with those of previous studies ${ }^{12,30,31}$, which reported that earlier intervention is better than delayed management. Males made up most of the sample in the current study $(81.8 \%)$, which follows a number of previous studies ${ }^{12,32}$ showing that males are more susceptible to mandibular fractures than females.

In the present study, dehiscence of the wound did not occur in the anterior and body regions. This may be due to the very low profile (only the screw head) placed under the wound, which allows a relaxed suturing technique. Clinically, complications were minimal in except for $12.1 \%$ of patients who reported mental nerve effects. However, mental nerve recovery did not require prolonged time. This effect may be attributed to the mental nerve and soft tissues stretching during surgery. Moreover, the lag screw was applied more rapidly than other techniques are typically applied ${ }^{23}$. In the present study, the mean time required to place two lag screws was $53.67 \pm 5.099$ minutes. The duration and severity of neurosensory disability were directly related to the amount of trauma inflicted on the mental nerve ${ }^{33}$.

Occlusion was obtained in all cases after CLSFT in the present study. However, in angle fractures it appears that a single lag screw is not sufficient, and these patients required 2 weeks of MMF in 3\% of cases. However, $100 \%$ bone healing was obtained in all cases, and this agrees with the main goal of fixation as outlined by Miles et al. ${ }^{34}$.

In this study, no infections were identified postoperatively in the symphyseal and parasymphyseal regions. No complications such as fracture segment malpositioning or severance of neurovascular structures or teeth were found in any case. This finding is consistent with those of several studies ${ }^{27,28,35,36}$ reporting that rigid fixation produces better, uncomplicated healing outcomes than traditional methods. However, others concluded that postoperative fracture line infection rate did 
not differ according to the technique used. Such results are contrary to those of Kallela et al. ${ }^{20}$ and Ellis and Ghali ${ }^{6}$, who reported $11.7 \%$ and $4.9 \%$ infection rates in parasymphyseal fractures, respectively.

Correct repositioning of fracture segments during surgery was obtained in all groups, and radiographic observation at postoperative one month revealed no interfragmentary gaps between bone ends, which means that no formation of callus was observed. This is consistent with the principle of direct bone healing, which allows absolute immobilization as in rigid fixation so that the full strength of the bone is restored more rapidly.

Forrest ${ }^{29}$ treated five patients suffering from anterior mandibular fractures using lag screws and concluded that lag screws can be applied with minimum exposure, thus reducing morbidities such as swelling, scarring, and nerve injury. Moreover, Nyárády et al. ${ }^{37}$ treated 468 patients suffering from alveolar fractures using transgingival lag screws and recommended this technique when the blood supply is jeopardized and MMF cannot be used.

Huang et al. ${ }^{38}$ evaluated clinical results in 12 patients who suffered from anterior mandibular fractures that were fixed using lag screws. They concluded that lag screw fixation can achieve good stability, appropriate compression with reduced surgical time, and promote osseous healing without the need for plate adaptation.

The need for affordable equipment in developing countries requires the use of the cheapest osteosynthesis fixation techniques possible ${ }^{12}$. To avoid waiting for the purchase of appropriate plates and screws, the use of CLSFT is the cheapest option available in these situations. The single long CLSFT used in the current investigation costs 600 Egyptian pounds, which is equivalent to \$38 USD and therefore costs much less than bone plates. Such cost savings are beneficial in low socioeconomic status countries.

The success rate reported in this study maybe be related to early presentation to operation. The limitation that we found in this study was that the removal of these devices could be very difficult after healing, as is usually indicated with other fixation devices (plates and screws are usually removed after 6 months). Although this may be a problem, in the present study none of the patients returned to have these screws removed.

\section{Conclusion}

Our clinical experience indicates that CLSFT is the most cost-effective and rapid technique for fixation of mandibular fractures, producing good treatment results with very limited complications. However, this technique is sensitive and requires surgical expertise. It may be applied to most mandibular fractures with specialized characteristics, as follows:

- Fresh sagittal split (true symphyseal) fractures.

- Single straight line, parasymphysis fractures directed anteriorly at the inferior border were more accessible. Fracture segments that were posteriorly directed and comminuted or cracked were not favorable.

- Long chins with curved or curled anterior regions are ideal for the application of two lag screws.

- Standardized indications of oblique transverse surface fractures in the anterior, body, and angle regions.

- CLSFT is not indicated in comminuted fractures, old, or delayed fractures, or in missing segment or gap fractures (in cases where compression is contraindicated).

\section{Author's Contributions}

S.A.H.E. collected the data, wrote the manuscript, designed the research and performed the statistical analysis. The author read the final manuscript and approved it.

\section{Acknowledgements}

The author would like to thank Dr. Susan Hassan and Dr. Hatem Alahmady, Professors of Oral and Maxillofacial Surgery, Al-Azhar University, Cairo, Egypt, for their great help, mentorship and scientific support. Many thanks to Dr. Fatma Khalifa, Associate Professor of Oral and Maxillofacial Surgery, Al-Azhar University, Egypt, for her great help and support.

\section{Ethics Approval and Consent to Participate}

This study was reviewed and ethically approved by the AlAzhar University Ethical Committee Board (No. PD-P-020004) and all patients provided written informed consent prior to surgery.

\section{Conflict of Interest}

No potential conflict of interest relevant to this article was reported. 


\section{References}

1. Goyal M, Jhamb A, Chawla S, Marya K, Dua JS, Yadav S. A comparative evaluation of fixation techniques in anterior mandibular fractures using $2.0 \mathrm{~mm}$ monocortical titanium miniplates versus $2.4 \mathrm{~mm}$ cortical titanium lag screws. J Maxillofac Oral Surg 2012;11:442-50. https://doi.org/10.1007/s12663-012-0342-1

2. Tiwari M, Meshram V, Lambade P, Fernandes G. Titanium lag screw versus miniplate fixation in the treatment of anterior mandibular fractures. J Oral Maxillofac Surg 2019;77:1031-9. https:// doi.org/10.1016/j.joms.2019.01.001

3. Emam HA, Stevens MR. Can an arch bar replace a second lag screw in management of anterior mandibular fractures? J Oral Maxillofac Surg 2012;70:378-83. https://doi.org/10.1016/ j.joms.2011.08.010

4. Kim MR, Oh JH, Choi JW. Prognosis following the lag-screw fixation for the fractured mandibular condyle. J Korean Assoc Oral Maxillofac Surg 1997;23:696-703.

5. Brons R, Boering G. Fractures of the mandibular body treated by stable internal fixation: a preliminary report. J Oral Surg 1970;28:407-15.

6. Ellis E 3rd, Ghali GE. Lag screw fixation of anterior mandibular fractures. J Oral Maxillofac Surg 1991;49:13-21; discussion 21-2. https://doi.org/10.1016/0278-2391(91)90259-o

7. Agnihotri A, Prabhu S, Thomas S. A comparative analysis of the efficacy of cortical screws as lag screws and miniplates for internal fixation of mandibular symphyseal region fractures: a randomized prospective study. Int J Oral Maxillofac Surg 2014;43:22-8. https:/ doi.org/10.1016/j.ijom.2013.07.001

8. Serletti JM, LeTourneau PR, Smith A, Coniglio JU, Popat S, Losee JE. Transverse lag screw fixation in midline mandibulotomy: a case series revisited. Plast Reconstr Surg 2004;114:178-85. https:// doi.org/10.1097/01.prs.0000128381.15075.5f

9. Thoma KH. Methods of fixation of jaw fractures and their indications. J Oral Surg (Chic) 1948;6:125-34.

10. Terheyden H, Mühlendyck C, Sprengel M, Ludwig K, Härle F. Self-adapting washer system for lag screw fixation of mandibular fractures. Part II: in vitro mechanical characterization of 2.3 and 2.7 $\mathrm{mm}$ lag screw prototypes and in vivo removal torque after healing. J Craniomaxillofac Surg 1999;27:243-51. https://doi.org/10.1016/ s1010-5182(99)80036-5

11. Rao E, Naveen S, Rao RC, Kollabathula K, Srirambhatla M, Gandham S. Principle of lag-screw fixation in mandibular trauma. J Int Soc Prev Community Dent 2019;9:282-9. https://doi.org/10.4103/ jispcd.JISPCD_64_19

12. Elsayed SA, Mohamed FI, Khalifa GA. Clinical outcomes of three different types of hardware for the treatment of mandibular angle fractures: a comparative retrospective study. Int J Oral Maxillofac Surg 2015;44:1260-7. https://doi.org/10.1016/j.ijom.2015.07.005

13. Ellis E 3rd. Use of lag screws for fractures of the mandibular body. J Oral Maxillofac Surg 1996;54:1314-6. https://doi.org/10.1016/ s0278-2391(96)90489-9

14. Petzel JR, Bülles G. Stability of the mandibular condylar process after functionally stable traction-screw-osteosynthesis (TSO) with a self-tapping screw-pin. J Maxillofac Surg 1982;10:149-54. https:// doi.org/10.1016/s0301-0503(82)80032-5

15. Pilling E, Schneider M, Mai R, Loukota RA, Eckelt U. Minimally invasive fracture treatment with cannulated lag screws in intracapsular fractures of the condyle. J Oral Maxillofac Surg 2006;64:86872. https://doi.org/10.1016/j.joms.2005.11.049

16. Schneider A, Schulze J, Eckelt U, Laniado M. Lag screw osteosynthesis of fractures of the mandibular condyle: potential benefit of preoperative planning using multiplanar $\mathrm{CT}$ reconstruction. Oral Surg Oral Med Oral Pathol Oral Radiol Endod 2005;99:142-7. https://doi.org/10.1016/j.tripleo.2004.05.021

17. Eckelt U, Hlawitschka M. Clinical and radiological evaluation following surgical treatment of condylar neck fractures with lag screws. J Craniomaxillofac Surg 1999;27:235-42. https://doi. org/10.1016/s1010-5182(99)80035-3

18. Niederdellmann H, Schilli W, Düker J, Akuamoa-Boateng E. Osteosynthesis of mandibular fractures using lag screws. Int J Oral Surg 1976;5:117-21. https://doi.org/10.1016/s03009785(76)80059-2

19. Madsen MJ, McDaniel CA, Haug RH. A biomechanical evaluation of plating techniques used for reconstructing mandibular symphysis/parasymphysis fractures. J Oral Maxillofac Surg 2008;66:20129. https://doi.org/10.1016/j.joms.2008.06.013

20. Kallela I, Ilzuka T, Laine P, Lindqvist C. Lag-screw fixation of mandibular parasymphyseal and angle fractures. Oral Surg Oral Med Oral Pathol Oral Radiol Endod 1996;82:510-6. https://doi. org/10.1016/s1079-2104(96)80195-8

21. Kallela I, Söderholm AL, Paukku P, Lindqvist C. Lag-screw osteosynthesis of mandibular condyle fractures: a clinical and radiological study. J Oral Maxillofac Surg 1995;53:1397-404; discussion 1405-6. https://doi.org/10.1016/0278-2391(95)90663-0

22. Tiwana PS, Kushner GM, Alpert B. Lag screw fixation of anterior mandibular fractures: a retrospective analysis of intraoperative and postoperative complications. J Oral Maxillofac Surg 2007;65:11805. https://doi.org/10.1016/j.joms.2006.11.046

23. Wusiman P, Taxifulati D, Weidong L, Moming A. Three-dimensional versus standard miniplate, lag screws versus miniplates, locking plate versus non-locking miniplates: management of mandibular fractures, a systematic review and meta-analysis. J Dent Sci 2019;14:66-80. https://doi.org/10.1016/j.jds.2018.04.004

24. Niederdellmann H, Akuamoa-Boateng E, Uhlig G. Lag-screw osteosynthesis: a new procedure for treating fractures of the mandibular angle. J Oral Surg 1981;39:938-40.

25. Elsayed SAH, Elsayed EH, Altaweel AA. Stabilization of anterior mandibular fracture using different osteosynthesis devices: perioperative clinical notes. Oral Maxillofac Surg 2020. https://doi. org/10.1007/s10006-020-00917-9 [Epub ahead of print]

26. Ellis E 3rd, Graham J. Use of a 2.0-mm locking plate/screw system for mandibular fracture surgery. J Oral Maxillofac Surg 2002;60:642-5; discussion 645-6. https://doi.org/10.1053/ joms. 2002.33110

27. Sauerbier S, Kuenz J, Hauptmann S, Hoogendijk CF, Liebehenschel N, Schön R, et al. Clinical aspects of a 2.0-mm locking plate system for mandibular fracture surgery. J Craniomaxillofac Surg 2010;38:501-4. https://doi.org/10.1016/j.jcms.2010.01.001

28. Miloro M, Ghali G, Larsen P, Waite P. Peterson's principles of oral and maxillofacial surgery. Hamilton: BC Decker; 2004.

29. Forrest CR. Application of minimal-access techniques in lag screw fixation of fractures of the anterior mandible. Plast Reconstr Surg 1999;104:2127-34. https://doi.org/10.1097/00006534-19991200000028

30. Yang SB, Jang CS, Kim JW, Yim JH, Kim JY, Yang BE. The prospective preliminary clinical study of open reduction and internal fixation of mandibular angle fractures using 2 miniplates. J Korean Assoc Oral Maxillofac Surg 2010;36:320-4. https://doi. org/10.5125/jkaoms.2010.36.4.320

31. Lee $\mathrm{CH}, \mathrm{Kim} \mathrm{CH}$. Open reduction of mandibular fracture without maxillomandibular fixation: retrospective study. J Korean Assoc Oral Maxillofac Surg 2011;37:255-63. https://doi.org/10.5125/jkaoms.2011.37.4.255

32. Motamedi MH. An assessment of maxillofacial fractures: a 5-year study of 237 patients. J Oral Maxillofac Surg 2003;61:61-4. https:// doi.org/10.1053/joms.2003.50049

33. Iizuka $\mathrm{T}$, Lindqvist $\mathrm{C}$, Hallikainen $\mathrm{D}$, Paukku P. Infection after rigid internal fixation of mandibular fractures: a clinical and radiologic study. J Oral Maxillofac Surg 1991;49:585-93. https://doi. org/10.1016/0278-2391(91)90340-r

34. Miles BA, Potter JK, Ellis E 3rd. The efficacy of postoperative antibiotic regimens in the open treatment of mandibular fractures: a 
prospective randomized trial. J Oral Maxillofac Surg 2006;64:57682. https://doi.org/10.1016/j.joms.2006.01.003

35. Choi KY, Yang JD, Chung HY, Cho BC. Current concepts in the mandibular condyle fracture management part II: open reduction versus closed reduction. Arch Plast Surg 2012;39:301-8. https:// doi.org/10.5999/aps.2012.39.4.301

36. Chen S, Zhang Y, An JG, He Y. Width-controlling fixation of symphyseal/parasymphyseal fractures associated with bilateral condylar fractures with 2 2.0-mm miniplates: a retrospective investigation of 45 cases. J Oral Maxillofac Surg 2016;74:315-27. https:// doi.org/10.1016/j.joms.2015.09.030

37. Nyárády Z, Orsi E, Nagy K, Olasz L, Nyárády J. Transgingival lag-screw osteosynthesis of alveolar process fracture. Int $\mathrm{J}$ Oral Maxillofac Surg 2010;39:779-82. https://doi.org/10.1016/ j.ijom.2010.01.022

38. Huang LJ, Ma XZ, Ruan TG. [Use of cortical (lag) screws in internal fixation of mental fractures]. Shanghai Kou Qiang Yi Xue 2004;13:214-6. Chinese.

How to cite this article: Elsayed SAH. Cortical lag screw fixation for the management of mandibular injuries. J Korean Assoc Oral Maxillofac Surg 2020;46:393-402. https://doi.org/10.5125/ jkaoms.2020.46.6.393 